\title{
Achievement of Renewable Energies Considering Modern Technology
}

\author{
Masoumeh Jamali Estalkh Zir* \\ Department of Architects, Khalkhal Branch, Islamic Azad University, Khalkhal, Iran
}

\begin{abstract}
The limited fossil energy resources and problems caused by greenhouse gas emissions has made it clear for all regarding the need for more attention to renewable energies. Since renewable energies contain various and diverse sources which are created by natural and available energies. Nowadays, due to the increasing population and human needs and consequently, an increase in energy consumption, the energy crisis phenomenon is observed in the world. Excessive consumption of energy derived from fossil fuel is along with the rapid growth of communities' economic that due to climate change, environmental protection and local economic development, fossil energies decrement and increasing demand for energy results in making use of new energy sources such as wind, water, biogas and geothermal energy sources that are clean energy sources. Studies conducted in this regard, indicate that development of new energies' use can play an important role in increasing the country's energy system's security grade. In this article, along with indicating the definition and explanation of the various renewable energy, we have introduced various types of this energy including wind energy, solar energy, biomass, geothermal energy and moon gravitation energy, and we have examined the need to prepare and make use of these energies.
\end{abstract}

Key Words: Energy and renewable energy, challenges, modern energies development, modern technology

\section{INTRODUCTION AND STATEMENT OF PROBLEM}

Undoubtedly, energy is an essential and unavoidable issue for having development in a country, since energy sources is one of the most important elements which is effective in permanent development of a country. Having appropriate energy is the most important economic factor of industrial communities after manpower. Energy is an essential demand for permanent economic development, social welfare, life quality improvement and community's security. In case of producing and using energy in a way to provide human development in longtime in all the economic, social and environmental dimensions, the concept of permanent energy will be fulfilled. Therefore, providing permanent energy is a need for permanent development of a county. Due to this reason, in recent years, various countries including developed and developing ones have focused excessive attention to renewable energy (solar energy, wind energy, geothermal energy, etc.) in order to create variety in using the sources and reducing dependence on an energy carrier and environmental considerations on achieving permanent energy. Rising in fossil fuels' price, environmental considerations, energy provision security, application in petro chemistry, technology development, and economic justification in some cases are mostly the determinants of the renewable energies' future. Notwithstanding, this area is transitory permanently and the future of these transitions is indicator of price reduction and its penetration expansion in the world's energy market and permanent energy achievement (Kabi Nezhadiyan, 2008).

Due to fossil fuels' storage reduction, pollutants' increment and its consequent climate changes in aerospace; producing and making use of new sources of renewable energy which emission less pollution, is a necessity. Among the energy sources, fossil sources and the energy resulted from nuclear fusion to some extent and water powerhouses have major role in energy provision in the world and the other energy sources have not expanded adequately yet. Among these types of energies, there are sources which are called renewable energies. Renewable energy sources have high potential in fulfilling energy demands especially in the developing countries (Pfeiffer \& Mulder, 2013).

Also, in Iran, various systems including power ministry and oil ministry are responsible for supporting energy renewable sources' use expansion including wind, solar, geothermal, small hydro, marine and biomass energies (energy consumption pattern reform's law, 2010). The evidence demonstrates that although Iran's potential for using renewable sources is high, they have not been used in an efficient manner yet (Fadai et al., 2011). The issue is that transition from traditional energy system towards renewable energy system and effective use of renewable energies has high dependence to renewable energy technology's diffusion (Tsoutsos \& Stamboulis, 2005) and the evidence demonstrates that despite spending years on attempts for renewable energy technology's diffusion, the process of renewable energy technology's diffusion has been too slow and difficult (Nrgro et.al., 2012). 
Due to the demand of developing countries, the amount of using renewable energies is also increasing in the world's countries, so that one of the expansion indexes is energy use, compatible to the set plans, this energy has created more share in energy provision system.

Appropriate channel for expanding renewable energies in all the countries is considered supports, creative governmental policy, existence of appropriate channels for investing and technology transfer to the developing countries. Renewable energy industries are being settled in transition point now and from technical viewpoint, there has been their offer ability and in economic viewpoint, there has been competition in most of the cities of our country; therefore, after finishing oil products' sources and the world problem of global warming, it will assist developed counties in national interests' advancement. These industries can maximize productivity in investment in the field of expansion and completion of energy resumption technology in the markets of each country.

It seems that three major factors exist in market capacity expansion that the first of them has been national energy security. The investigations demonstrate that oil utilization is increasing and soon it will pass from high internal production, to the extent that it will make developed countries dependent on the oil markets increasingly. The result of this issue will be the vulnerability of the economy of western countries confronting with whatever disorder is related to oil importation. The rapid growth of developing countries will provide increasing pressure on world oil markets, so that by time pass, the condition will be worsen and deteriorated; therefore, renewable energy will help western countries to rely on internal energy sources and accordingly will result in reduction of their demands to fossil fuels and reduction in consumption growth.

The major factor of the current problems in relation with renewable energy had been on worries regarding climate changes, renewable energy can provide energy demand and moreover and reduces the greenhouse gas emissions. Greenhouse gas also like dioxide carbon and methane are accumulated in thin layer of earth climate regularly and this accumulation of gas increases the earth' temperature increasingly. Unfortunately, temperature increment will lead to disastrous potential and negative results; therefore, attempts should be taken for its avoidance that making use of renewable energies without carbon will be one of these ways.

\section{ENERGY AND RENEWABLE ENERGY}

Since early human beings have started using energy till now, energy in classified into old and modern energy. Old energies include: wood, coal, wind energy (for wind ships), oil, etc.

Modern energies include: solar energy, wind (for current wind machines), hydrogen, atom, nuclear energy, etc. Based on this, if we can define energy as "saved work" or "the ability to do the work", we have been able to present a definition of energy to some extent; although, the definition is not comprehensive and complete (Seyyed Razi, 2005).

In definition of energy, we can state that: energy is the ability to do a task. It means that all the creatures should consume food for doing task so that the food is saved in their muscles in energy form to use it in the case of demand. Through technologic development and revolution, all the tools and cars make use of various energies is a manner. For instance, if car does not use fuel, cannot do a task for us or provided that the refrigerator does not use electrical energy, cannot do cooling operation. In points of the fact, energy is always transformed from a form to another and this issue carries out the tasks. As a sample, the present energy in the lakes behind dams have elevation energy. Moving cars like most of the other movable objects, have kinetic energy. In bow shooting, tensile energy is hidden and in rainy cloudy, we can also find electrical energy (Seyyed Razi, 2005).

In points of the fact, renewable energy is a type of energy which has the capability of returning to the nature in contrast with unrenewable energies. Wind energies, solar, geothermal, biomass, biofuel, and hydroelectric power are among these types of energies. The potential of renewable energy sources for fulfilling the energy demand of the world is high. These energies except cleaner effects are interesting options for economic growth, fulfilling energy demands, creating employment, and creating productive industry and service in comparison to fossil fuels which particularly can have abundant attraction in the developing countries (Pfeiffer \& Mulder, 2013).

\section{The reasons for approaching these energies}

1- Impermanence and renewability of these energies

2- Reducing environmental pollution

3- The possibility of accessing productive technology such as energies in the country which results in lack of dependence to the other counties.

4- Having the potential and high abilities of new energy sources including direct and longtime radiation of sun ray, fairly permanent wind existence with high speed is some points of the country, geothermal energy source in most parts of the country... (Dariyush Foroughi, 1996). 


\section{Significance of the study}

Since oil and gas applications are more widespread and its use is easier. In the recent decade, these two material have been used a lot and coal as the third fossil fuel has been used less and its storage will endure for a long time, coal can be reckoned as a solid fuel by further 400 years. Of course, there is the possibility of using coal as liquid gas. Even in the middle- earth, coal cab be converted to liquid fuel by spending high costs.

It is noteworthy that maintaining coal (or any other fuel) does not only mean its lack of using, but it means better use of it. Energy engineers have to some extent improved the extraction ways of energy resultant from coal. The new methods even promise better uses. Through using the principles based on plasma physics and magnet hydrodynamics, electricity can be produced from the flame itself. Considering the current social and economic up and downs, expanding the alternative energy sources is a necessary, urgent, and unavoidable issue, even using coal instead of oil or transforming coal into oil for removing abundant demands internal combustion engine (smolder) means great investment sources allocation.

The new energy sources which are renewable are approximately various and abundant. Wind energy, bioenergy, wave energy, sea thermal gradient energy, geothermal, fusion energy and water energy are some instances of the new energy sources. Of course, it is noteworthy that all these energy sources have been existed for earlier times but growth and expansion in knowledge and technology has made mankind in bridling these energies (Godfrey, 2007).

\section{1- Energy sources' limitation}

The alarm signal regarding the world's sources limitation was sounded by Pecchi Italian business man A. Kingura, the manager of OFCD who is one of the of the administrators of Rome club organization. In a report titled growth limitation, they have announced energy limitation that energy limitation along with the world's dependence to fossil fuels' application particularly oil will shock the world, the oil which constitutes the unavoidable source of economic growth of and its price has led to reaction and sensitivity by international community (Kabinezhadiyan, 2008).

The energy source especially fossil energy that we utilize is not unlimited. Considering the point that meticulous understanding of the amount of energy sources is difficult, but in regard to fossil energy including oil, gas, and coal, through expanding excavation and statistical methods predict the fossil energy sources storage (country's management and budgeting organization).

\section{2- Environmental pollution of energy sources}

Environmental problems which have been introduced in 1990 decade as the global and unavoidable crisis, is eventually depends on energy. Particularly, the globe's heat resultant from greenhouse gases' viscosity increment like dioxide carbon and methane and their effects on reducing agricultural products and climate change and acid rains resultant from nitrogen oxide and sulfur oxide and so on resulted from fossil fuels lead to damaging forests, lakes, lagoons, etc. among the greenhouse gases which result in globe's heat, dioxide carbon has the most role (Nasiri, 2005).

In the other hand, the amount of outcome all over the world has increased significantly after industrial revolution especially after world war and recently it is increasing in the developing countries (the country's management and budgeting organization).

\section{The introduction of renewable energies 1. Solar Energy}

The gravitational potential energy increases the heat in the sun, as far as the temperature condition is provided for nuclear fusion. Due to this reaction, the matter becomes converted into the energy in which is the form of radiation, and is enough that both keeps the sun hot and provides the heat of the solar system and the earth. At the ground level, the great source can be used optimally by converting the energy to the other forms.

The sun radiation is the biggest source of renewable energy on the earth and if just 1 percent of the world's deserts be utilized with the solar thermal power stations, this amount will be enough for generation of the world's demanding annual electricity. There are two ways for getting profit of the solar energy:

a. The direct use of the sunlight and converting it to the electricity through photovoltaic cells.

b. The direct use of the solar system and converting it to other forms of energies (Mousavifar, 2007:881).

2. Wind and wave's energy

Wind is one of the manifestations of solar energy and identically the dynamic air and the small component of the sun radiation in which reaches out to the atmosphere and turns to the wind energy. The global warming and its atmosphere cause the convection currents unequally (convection) as well as the relative motion of the atmosphere produces the wind ratio to the earth. With the development of the environmental attitudes and frugality strategies in utilization of nonrenewable energy source, the use of the wind power compared with other considered energy sources has increased in some countries of the world. The use of the wind turbines technology can be an appropriate choice compared with other renewable energy sources (Mazreati, 2006: 518).

DOI: 10.9790/0837-2205093845 $\quad$ www.iosrjournals.org $\quad 40 \mid$ Page




\section{The advantages of the wind energy}

One of the advantages of the wind energy is that, the wind blow is faster in winter and more electricity is produced when more power is needed. This energy has an inexhaustible energy and the technology tested source without producing pollution. Consistently recent developments in industry, is reduced the cost of the electricity produced by wind turbine generators; this amount is less than the cost of the electricity produced by coal and nuclear fission and is economically competitive with any other items. Also like other renewable and continuous energies it doesn't have much opponents (Mazreati, 2006; 523).

\section{Wind energy inefficiencies}

Many people say wind turbine generators are apparently unpleasant and blatant; especially they are because located in beautiful places outside of the urban areas. It should be said that the generator which its fuel is coal, will naturally be uglier and noisier than windmill towers. The consecutive noise of the windmill turbine towers is considered as an important issue for those who are near to them. Now the sound of these generators can be controlled by the help of gears technology and three-blade turbines.

a. The low prices of wind power turbines compared with other renewable energies.

b. Help in creating employment in the country (Mousavifar, 2007; 885).

Due to the windy areas in Iran, the design and the construction of windmills were common 2000 years before Christ and already the appropriate platform is also provided in order to expand utilization of wind turbines. Wind power generators can be a good alternative for gas and steam power plants. The studies and evaluations done in the field of wind energy potential in Iran have shown, that only in 26 areas of the country (including more than 45 suitable sites) considering the overall efficiency of $33 \%$, the nominal capacity of the sites is about $6500 \mathrm{MW}$ and this is the condition, in which the nominal capacity of total power plants in the country is already 68932 MegaWatt. In wind turbines, the kinetic energy of the wind becomes converted into the mechanical energy and then into the electrical energy. The technical use of the wind energy is only possible, when the average speed of wind is in the range of $0 / 5$ to $0 / 25$. The exploitable wind energy potential in the world is estimated 110 Ega Jules (each Ega Jules is equivalent to 1018 Jules), that the mounted capacity of this amount, is 40 Megawatt by the end of the year 2003 (2003 hijri) in the world (Ghader, Daneshi, 2008; 582).

The advantages of using this energy is, no need of the fuel for wind turbine, supplying part of the electricity demands, proportional lessens of the wind energy ratio to the fossil energy, diversify the energy sources and create a sustainable energy system, high maneuverability in operation (from a few watts to several megawatts), no need for water and lack of environmental pollution (Ghader Daneshi, 2008; 858).

\section{Small wind turbines:}

The small wind turbines are used for supplying the consumer island electricity or areas where the supplying the electricity is difficult through the national grid. These turbines have the ability to generate electricity up to 10 kilowatts.

\section{The average wind turbines:}

Generally generating these turbines is between 10-250 kilowatts. These turbines are used for supplying the residential, commercial, industrial and agricultural expenditure.

\section{Large wind turbines (wind farms):}

Typically, these turbines include several centralized wind turbines with the production capacity of $250 \mathrm{KW}$ up, that are designed in the form of network connected or network isolated (Ghder Daneshi, 2008; 590).

Nowadays the use of wind energy technology has been available in many countries and the difficulties of solar energy has been diagnosed as a cheapest way for generating electricity. The valuation of the produced energy depends both on the environmental and functional factors and the types of the used machines. The different studies done in the field of the wind energy's used price, shows that, although the price of the wind machines increases with their greatness and the boost of approximate power, but the cost of per kilowatt of their energy decreases (Kabinezhad, 2007).

\section{Geothermal energy}

Geothermal energy, is the recoverable thermal energy from the crust of the earth. Geothermal energy despite of other renewable energies is the source of a constant energy with the access factor of $100 \%$ that is exploited day and night during the year (world energy council, 1996). The geothermal energy is used in two parts of power (direct) and non-power (indirect) applications. Production of electricity from geothermal sources is now done in 22 countries of the world, that total nominal power ration of all power plants from this energy is more than 8000 Megawatts. This is while, more than 64 countries of the worldwide are using installed capacity of more than 15000 thermal Megawatts of this energy source in non-power plant applications (Mousavifar, 2007; 886). 
One can point out the items such as, construction of hydrotherapy and tourist resorts centers, heating of greenhouses, construction of fish and poultry breeding centers, prevent icing roads in winter, supplies of heating and cooling of buildings by geothermal heat pumps from the direct use of geothermal energy (Mousavifar, 2007; 890).

The word geothermal comes from a combination of two Greek words, Geo meaning earth and thermal meaning heat, in simple terms, geothermal energy was actually thermogenesis, which is driven out of the earth through layers of the earth. The steam and the hot water produced in the depth of the earth is used for heating buildings or making electricity. Geothermal energy is an appropriate renewable energy source, because rainfall causes the water to be replaced and the heat is alternatively produced in the depth of the earth (Modern renewable energy sources, 1996).

\section{Thermal energy right places}

Frequently, the geothermal energy sources were located in the depth of the earth and there are no certain signs to find them at the ground level. Geothermal energy sources are transmitted partly in shape of a volcano, smoke and steam from the crater gap, hot springs and geysers to the ground. Most of the volcanic activities in the world take place in the area called the ring of fire. Some of the applications of the geothermal energy use the temperature near the surface, whereas others require very deep wells in the earth, so three main applications of geothermal energy include the following:

1 - The heating systems and the right use of the hot water that is contracted in ponds and water reservoirs near the surface.

2- Electricity production at the power plant that requires water or steam to have a very high temperature. Geothermal power plants are located in a place where the geothermal energy sources are located at the depth of one or two miles from earth's surface.

3- Geothermal heat pumps using the solid and hard ground and the heat of water near the surface to control the air temperature on the earth (Kabinezhad, 2007).

\section{4- Hydrogen technology, fuel cell and biomass}

Although the widespread and massive energy consumption derived from fossil fuels has brought the rapid economic growth in advanced industrial societies, but due to the emission of combustion and increased carbon dioxide in the atmosphere and its consequence, has prepared the world with ever increasing changes where the increase in global temperature, climate changes, rising sea levels, and finally escalation of international conflicts are among these consequences. On the other hand, the imminent completion of fossil resources and anticipated price increases is important for the importance and the need for replacing the current energy system (Mazreati, 2006; 512).

Nearly all renewable energy sources are available periodically and are not portable or portable storage so they cannot be used in the form of fuel especially in transportation. Clean fuels have physical and chemical properties, which makes them cleaner than gasoline with current composition and structure during combustion. These fuels produce fewer pollutants during combustion, in addition, the use of these fuels is greatly increased and decreases the accumulation of carbon dioxide which thereby warming the earth. Hydrogen as a clean fuel can be a good alternative for other common fuels and can be raised as an energy carrier in the future. Frequency of water production facility, almost unique and inherent environmental benefits of hydrogen consumption is among the features that distinguishes it compared to other proposed fuel options. Hydrogen can be produced using a variety of primary energy sources and can be used in all cases and applications of fossil and fuels. Hydrogen completes the renewable energy sources and make them available in an appropriate way in any place and any time, and provides them to consumers (Mazreati, 2006; 528).

\section{5- Hydropower}

Water like wind and sun is from natural energy sources. The hydropower is due to its power and energy. By closing the dam at the river, one can store kinetic energy into potential energy and leaded it to different expenditure. The waterfalls also, are a huge source of water energy due to altitude and the high speed of water (Ghader Daneshi, 2008; 899).

Watermills have been used maybe three thousand years ago, the old mills had old wheels that were mounted on vertical bars. Romans had used the mills with vertical wheels, in the sixteenth century the hydropower came in the form of artistic, the advanced technology in large scale production of electrical energy from water was created in the nineteenth century. The hydropower is a renewable source (reversible energy) and is depended on solar energy (Nasiri, 2005).

\section{6- Fossil energies}

Fossil is the remaining of the plants and the animals that are buried in the ground in the past. These decaying remains can be used in the production of fossil fuels and energy. These fuels are naturally mined, in the form of solid, liquid and gas or a mixture of these in mines (Mazreati, 2005; 520).

\begin{tabular}{lll}
\hline DOI: $10.9790 / 0837-2205093845$ & www.iosrjournals.org & $42 \mid$ Page
\end{tabular}




\section{7- Tidal energy}

The tides are related to the rising and getting down the sea levels, tide means getting down the water and flood tide means rising the sea level. Basically, the tides occur due to the interaction of gravity and systematic of earth, moon and sun. The effects of the sun and the moon on the earth, specifies the equilibrium tide theory. Tidal power generator of other celestial bodies is negligible due to the distance or the small mass. The tides have a significant impact on the earth-moon system's orbital parameters. The exact study of tides are involved on the motion of the moon. The total productive forces tide is small. The fundamental forces generating tides are due to the moon (Moloud, 2000).

\section{8- The moon gravity}

The moon is one of the significant renewable energy sources, so it has taken into consideration less than solar energy, that's why the harnessing the energy of the moon is arrived early in the twelfth century, that Britain, France and Spain are pioneer in this field. The moon gravity, was as a usable energy source of this bright star that creates the tides. The movement of the moon causes the water movement and the production of the energy, so according to the exploitation of this energy, the use of it has not spread yet in our country, so that we can search the cause at its cost, especially the construction of the large equipment and large turbines must be done in salted water which is difficult and reduces the life of the consumables and equipment (Ghader Daneshi, 2008; 591).

\section{Production of electricity from renewable energy:}

Currently105 countries have generated a variety of their actions in the development of renewable power generation that the most common form of actions and policies include the following:

1- Determination of tariff power purchase guarantee to consumers.

2- Portion of new energy sources from whole country's energy.

3- Determination of the initial investment subsidy or points to the consumer.

4- Providing investment tax credit or other tax credits.

5- Granted exemption from tax or exemption from value added tax.

6- Traded green certificates arising from the use of renewable energy.

7- Net metering and appropriate measures of power generation.

8- Direct investment of the government in this section.

9- Holding public tenders for electricity production right (Modern renewable energy sources, 1375).

\section{The development of renewable energy technologies in the country}

Expansion and the growth in the renewable energies sector, was caused enrichment and development of technology in order to implement sustainable renewable energy, which the following objectives can be followed:

a. The use of suitable standards and operational policies for the proper use of renewable energy technologies in order to promote the development of these energies that are appropriate in reducing the fossil energy.

b. Localization the manufacturing required equipment and planting them in order to strengthen the renewable energy technology and also optimization and using it for research and development and promoting these technologies in this industry in the country, that can have an effective role in reducing the consumption of fossil energies (Nasiri, 2005).

The contribution of renewable energies in primary energy basket, determining the capacity use of different technologies and the production of energy from renewables have been the other national targets of some countries.

With these explanations, specific objectives in the development of the determined relevant fuels are provided in some countries and in recent years some countries have put the year 2020 as the horizon prospects for the development of renewable energies. Besides, in our country, the government in the fifth development plan has done the necessary planning, that achieving these energies will be inevitable according to the global policy development (Nasiri, 2005).

\section{Renewable energy challenges:}

Unfortunately, due to the lack of necessary context in Iran, especially in past years there were obstacles to development and the use of renewable energies that some of them are already there. The most important ones are:

1- Availability of cheap and subsidized fuels, which has prevented the serious actions and operations for production of renewable energies broadly, that this problem is already remained. It is anticipated that, with the full implementation of the article 44 of the constitution and also the implementation of economic development plan, according to the year of economic Jihad in order to approach fossil fuel prices to the true value, the appropriate condition be provided for the renewable energy industry development in the country.

DOI: $10.9790 / 0837-2205093845 \quad$ www.iosrjournals.org $\quad 43$ | Page


2- The lack of comprehensive and suitable national program with quantitative criteria, that are legally established, although it was tried to predict and perform the quantitative and legal goals for the renewable energy industry development in this field, but the lack of the predicted sufficient credit allocation and also the mentioned mismatched quantitative targets with strategic and comprehensive information in this regard has caused the mentioned goals become realized practically.

3- Availability of structural problems based on the presence of several government agencies in renewable energy like ministry of agriculture, optimization of fuel consumption, automatic energy organization and ministry of power, were some of the other mentioned obstacles, which causes their dispersion and homogenization and consequently accomplishing the decentralized, low-effect and incomplete credit cost.

3- $\quad$ The private sector's entry to the field of renewable energy, had difficulties, so that in commercial areas like the wind, that is itself due to the renewable power purchase tariff compared with the high initial cost of investment in such power plants with conventional fossil plants, which use the low-cost fuel; that causes the rejection of demanded contracts by banks. on the other hand, the lack of a comprehensive legal basis and the items like time and the financing and credit resources' difficulty in order to long term guarantee shopping, the difficulty of finding land with requirements area, creation the wind plants and difficulty in obtaining permission in accordance with environmental legislation leads the confusion of the private sector in entering this industry (Foroughi, 1996).

\section{CONCLUSION AND SUGGESTION}

Although the new energies or clean energy is the achievement of the humankind's new knowledge for an individual, its root can be found in ancient civilization structure including Iran that have paved the way for posterity through scientific power and cogitation. Making use of solar energy and wind energy this country can be observed in the utilized techniques in traditional architecture of buildings and in dry areas.

Although the expansion of some of these techniques refers back to several thousand years ago, most of the cooling systems are used currently. Therefore, achieving clean energy has been attended by most of the scientists and researchers and they have attempted to make use of it in their everyday life.

Wind, geothermal, and solar energy possess good sources in our country that each of them are effective in reducing fossil fuels' usage. In relation with making use of geothermal energy which is produced through digging deep hole and hot water pumping or the earth' hot steam and is suitable for making the houses hot and producing electricity and also wind energy, the energies resultant form sea. With regard to solar energy, considering the point that sun is the biggest and the only source of proving the globe's energy, the sent energy is used in different ways and with the aim of proving the demanded energy for nonfossil fuels. Accordingly, through using photovoltaic system, it is converted directly into electrical energy. So, convenience in accessing to electrical energy resulted from solar electricity is one of its applications that in summary, making use of energy types is recommended in the country.

It is noteworthy that long term planning based on the current economical decision making pattern is the biggest problem confronting renewable energies' growth. These energies appear to demand high primary investing in comparison to fossil fuels, while they do not need current costs due to lack of demand to fuel while operating; accordingly:

- Reviewing and updating the economical decision making method.

- Increasing investing priority on renewable projects among financial institutions.

- Creating competitive market and exercising complete cost pricing system.

- Gradual removing of fossil energy subside and forwarding the income resultant from it towards providing investing budget in renewable energies.

- Encouraging the private sector in participating in investing in international energies and leading for increasing in making use of renewable energies.

- Increasing the budget to renewable energies' education and research sector is an unavoidable necessity for expanding and using renewable energies.

\section{REFERENCES}

[1]. Foroughi, Daiyush. (1996). Global energy association, Iran national committee of energy, energy for future world, Tehran.

[2]. Ghardaneshi, Abolghasem Ali, Adl, Mehrdad. (2008). Biogas in Iran (the current potential of the present extraction and future perspective).

[3]. Kabinezhadiyan, Abdolrazzagh. (2008). New energies' technology, Tehran.

[4]. Godfrey, Boil. (2007). Translation: Abdolrahim Partovi, new energies for permanent future, Tehran University publications, Tehran.

[5]. Seyyed Razi, Hossein. (2005). Renewable energies' introduction. First version, Naghous publications, Tehran. 
[6]. The country's management and budgeting organization, the first, second, third, fourth of economical, social and cultural expansion, Tehran, - $\quad$ The country's management and budgeting publications.

[7]. Global energy association, new renewable energy source. (1996). Tehran.

[8]. Moloud, Shiva. (2000). Hydrogen energy and its application in fuel cells, electricity conference of Hamadan Azad University.

[9]. Budgeting management, (2007). Tehran. Public relations of oil products' distribution national company.

[10]. Mousavifar, Ahmad. (2007). Energy's Global demand and the sources for its provision, the possible Ways for producing Hydrogen from technical and economical perspective, article series of the third national conference of energy, pp 883-890.

[11]. Mazraati, Mohammad; Ayatollahi, Mohammad. (Social costs and external effects of using fossil fuels in Iran, an opportunity to make use of permanent energies), article series of the third national conference of energy, pp 512-529.

[12]. Nasiri, Hossein. (2005). Expansion and permanent expansion: the third world perspective, Tehran.

[13]. Pfeiffer, B\& Mulder, P. (2013). Explaining the diffusion of renewable. Energy technology in developing countries.

[14]. Tsoutsos, T.D \& Stamboulis, Y.A. (2005). The sustainable diffusion of renewable energy techonologies as an example of an innovation- focused policy.

[15]. Fadai, D, Esfandabadi, Z.S. \& Abbasi. A (2011). Analyzing the causes of non- development of renewable energy - related industries in Iran.

[16]. Negro, S. O, Alkemade, F, \& Hekkert, m, p. (2012). Why does renewable energy diffuse so slowly? A review of innovation system problem. Renewable and sustainable energy Reviews. 